\title{
Enhanced Plasma GH Responses to Simultaneous Administration of TRH and GHRH in Patients with Primary Hypothyroidism
}

\author{
Kunihiko HANEW***, ATSUSHI UTSUMI*, AKIRA SUGAWARA*, AKI TANAKA*, \\ Hiroshi FUKAZAWA*, KATSUMI YOSHIDA* AND KEISHI ABE* \\ *The Second Department of Internal Medicine, Tohoku University School of Medicine, \\ Sendai 980 , and **Hanew Clinic, Sendai 980, Japan
}

\begin{abstract}
The mechanism of aberrant GH responses to TRH was indirectly evaluated in 7 patients with primary hypothyroidism. All patients showed GH response to TRH. When TRH was administered together with GHRH, the plasma GH response was much greater than after a single administration of TRH or GHRH (TRH+GHRH vs. TRH or GHRH: max. $\triangle \mathrm{GH}, 16.4 \pm 3.2$ vs. $5.4 \pm 1.3$ or $6.0 \pm 0.8 \mu \mathrm{g} / \mathrm{L}$; AUC, $1282.7 \pm 234.7$ vs. $384.0 \pm 95.0$ or $441.8 \pm 66.2$, both $P<0.01$ ). The combined administration of TRH and GHRH caused an additive, but not a synergistic, GH response. In contrast, 8 normal subjects showed neither any plasma GH response to TRH nor enhancement by TRH of GHRH-induced GH response following combined administration. It is concluded that the sites of action of TRH seemed to be different from GHRH in patients with primary hypothyroidism.
\end{abstract}

Key words: Plasma GH, TRH, GHRH, Primary hypothyroidism

(Endocrine Journal 42: 43-47, 1995)

PARADOXICAL growth hormone (GH) increase following TRH injection is often observed in various kinds of disorders, e.g. patients with acromegaly, anorexia nervosa, chronic renal failure, chronic hepatic failure, depression, schizophrenia, and primary hypothyroidism [1]. Although acromegalic pituitary adenoma possesses TRH receptors, it is not clear whether TRH receptor expression occurs in other disorders since these abberant GH responses disappear in patients with anorexia nervosa and depression after treatment [1,2]. It is reported that TRH and GHRH stimulate GH secretion from the rat pituitary gland through different intracellular transduction mechanisms [35]. In this connection, we have observed a synergistic $\mathrm{GH}$ increase in patients with acromegaly after the simultaneous administration of TRH

Received: April 18, 1994

Accepted: October 21, 1994

Correspondence to: Dr. Kunihiko HANEW, The Second Department of Internal Medicine, Tohoku University School of Medicine, 1-1 Seiryo-cho, Sendai 980, Japan and GHRH [6]. In rats, $\mathrm{GH}$ releasing activity of TRH is enhanced by GHRH pretreatment [7]. In this study we therefore examined plasma GH response to combined administration of TRH and GHRH in patients with primary hypothyroidism to indirectly evaluate the mechanism of action of TRH.

\section{Materials and Methods}

Seven untreated patients with primary hypothyroidism ( 2 males and 5 females, aged 23-72 yr), who had an aberrant GH response to TRH were studied (Table 1). As a control, 8 normal subjects (4 males and 4 females, aged 19-26 yr) were employed in this study. Informed consent was obtained from each subject.

Hypothyroid patients had decreased plasma thyroid hormone and increased basal plasma $\mathrm{TSH}$, and exaggerated TSH responses to TRH (Table 1).

Among these patients, the titer of thyroglobulin autoantibody was high in 3 patients (\# 5-7) and 
that of microsome autoantibody was high in 6 patients (\# 1, 2, 4-7).

After an overnight fast, all subjects were given TRH (500 $\mu \mathrm{g}$, iv) or GHRH (100 $\mu$ g, iv) individually or in combination, and blood sampling was performed $-30,0$ min before, and 15, 30, 45, 60, 90 and $120 \mathrm{~min}$ after the injection of the above agents. The AUC (area under the response curve) over the baseline was calculated by trapezoidal integration.

Plasma GH, PRL, TSH, $T_{3}, T_{4}$ and free $T_{4}$ were measured in duplicate with a commercial RIA kit (GH: Dainabot, Tokyo, free $\mathrm{T}_{4}$ : DPC, Tokyo), IRMA kit (PRL: Daiichi, Tokyo) and immunofluorometric assay kit (TSH, $\mathrm{T}_{3}, \mathrm{~T}_{4}$ : Pharmacia, Uppsala), respectively. The sensitivity to $\mathrm{GH}, \mathrm{PRL}, \mathrm{TSH}, \mathrm{T}_{3}$, $\mathrm{T}_{4}$ and free $\mathrm{T}_{4}$ was $0.2 \mu \mathrm{g} / \mathrm{L}, 0.3 \mu \mathrm{g} / \mathrm{L}, 0.02 \mathrm{mU} / \mathrm{L}$, $0.1 \mathrm{nmol} / \mathrm{L}, 2.6 \mathrm{nmol} / \mathrm{L}$, and $0.1 \mathrm{pmol} / \mathrm{L}$, and the intra- and interassay coefficients of variation were 4.1 and $4.7 \%$ for $\mathrm{GH}, 3.2$ and $5.6 \%$ for PRL, 4.0 and $5.6 \%$ for TSH, 3.0 and $6.1 \%$ for $\mathrm{T}_{4}, 2.9$ and $6.7 \%$ for $\mathrm{T}_{3}$, and 5.5 and $7.6 \%$ for free $\mathrm{T}_{4}$, respectively. All samples from an individual subject were analyzed in the same assay.

Data are expressed as the mean \pm SEM. Statistical analysis was carried out by analysis of variance followed by the Student/Newman-Keuls test and Fisher's randomization test.

\section{Results}

Plasma GH responses to TRH and GHRH individually or in the combination in 7 patients with primary hypothyroidism and in 8 normal subjects

The mean peak $\mathrm{GH}$ value after individual ad- ministration of TRH or GHRH was much greater than the basal value (basal vs peak: TRH, $1.1 \pm 0.5$ vs. $6.6 \pm 1.4 ; \mathrm{GHRH}, 1.6 \pm 0.7$ vs. $7.7 \pm 1.3 \mu \mathrm{g} / \mathrm{L}$, both $P<0.01$ ). When GHRH was administered together with $\mathrm{TRH}$, the plasma $\mathrm{GH}$ response was much greater than the response after single administration in terms of the mean value at 60,90 , $120 \mathrm{~min}(P<0.05-0.01)$ and the mean peak value $(\mathrm{TRH}+\mathrm{GHRH}, 18.0 \pm 3.7 \mu \mathrm{g} / \mathrm{L}$; vs. TRH, $P<0.01$, vs. GHRH, $P<0.05$ ) (Fig. 1, left panel). The AUC for the combined administration of TRH and GHRH $(1282.7 \pm 234.7 \mu \mathrm{g} /$ Lxmin) was also much greater than that for TRH $(384.0 \pm 95.0, P<0.01)$ or GHRH $(441.8 \pm 66.2, P<0.01)$ (Fig. 1$)$, but we could not find a significant difference between GH response to the combined administration of TRH and GHRH and sum of the response to a single administration of TRH and GHRH (max. $\triangle \mathrm{GH}: 16.4 \pm$ 3.2 vs. $11.0 \pm 1.7 \mu \mathrm{g} / \mathrm{L}$; AUC: $1282.7 \pm 234.7$ vs. $825.8 \pm 153.2 \mu \mathrm{g} /$ Lxmin, both $\mathrm{P}=\mathrm{NS}$ ).

The eight normal subjects did not show any response of plasma GH to the single administration of TRH, and these subjects did not show any enhancement of the response to the combined administration of TRH and GHRH, while the response pattern was somewhat suppressed until 60 min and enhanced thereafter by the combined administration (Fig. 2).

The peak plasma GH response to GHRH of hypothyroid patients was much lower than that of normal subjects $(32.2 \pm 6.8, P<0.01)$.

\section{Discussion}

In this study, patients with primary hypothyroidism showed an impaired $\mathrm{GH}$ response to

Table 1. Clinical and laboratory data in 7 patients with primary hypothyroidism

\begin{tabular}{|c|c|c|c|c|c|c|c|c|c|}
\hline \multirow{3}{*}{ Subjects } & \multirow{3}{*}{ Age (yr) } & \multirow{3}{*}{ Sex } & \multirow{3}{*}{$\begin{array}{c}\mathrm{T}_{3} \\
(\mathrm{nmol} / \mathrm{L})\end{array}$} & \multirow{3}{*}{$\begin{array}{c}\mathrm{T}_{4} \\
(\mathrm{nmol} / \mathrm{L})\end{array}$} & \multirow{3}{*}{$\begin{array}{c}\text { free } \mathrm{T}_{4} \\
(\mathrm{pmol} / \mathrm{L})\end{array}$} & \multicolumn{4}{|c|}{ Responses to TRH } \\
\hline & & & & & & \multicolumn{2}{|c|}{$\mathrm{TSH}(\mathrm{mU} / \mathrm{L})$} & \multicolumn{2}{|c|}{$\mathrm{GH}(\mu \mathrm{g} / \mathrm{L})$} \\
\hline & & & & & & Basal & Peak & Basal & Peak \\
\hline 1 & 23 & $\mathrm{~F}$ & 0.69 & 15.4 & 1.3 & 805.2 & 2428.8 & 0.2 & 5.0 \\
\hline 2 & 29 & $\mathrm{~F}$ & 0.83 & 32.2 & 6.4 & 38.8 & 308.2 & 0.3 & 2.6 \\
\hline 3 & 34 & $\mathrm{~F}$ & 0.73 & 21.9 & 1.3 & 194.7 & 398.4 & 3.2 & 6.8 \\
\hline 4 & 39 & $\mathrm{~F}$ & 0.88 & 43.8 & 6.6 & 6.9 & 87.8 & 0.4 & 4.6 \\
\hline 5 & 65 & $\mathrm{M}$ & 0.15 & 3.9 & - & 570.2 & 838.0 & 1.3 & 5.3 \\
\hline 6 & 67 & $\mathrm{M}$ & 0.48 & 42.5 & 1.3 & 13.7 & 57.4 & 0.2 & 7.7 \\
\hline 7 & 72 & $\mathrm{~F}$ & 0.30 & 9.0 & 1.0 & 159.1 & 324.9 & 2.4 & 14.8 \\
\hline
\end{tabular}

The normal range of $\mathrm{T}_{4}, \mathrm{~T}_{3}$, free $\mathrm{T}_{4}$, basal and peak TSH to TRH and basal GH is 57.9 to $193.1 \mathrm{nmol} / \mathrm{L}, 0.92$ to 2.77 $\mathrm{nmol} / \mathrm{L}, 10.2$ to $25.1 \mathrm{pmol} / \mathrm{L}, 0.3$ to $3.0 \mathrm{mU} / \mathrm{L}, 8$ to $27 \mathrm{mU} / \mathrm{L}$ and below $5 \mu \mathrm{g} / \mathrm{L}$, respectively. 

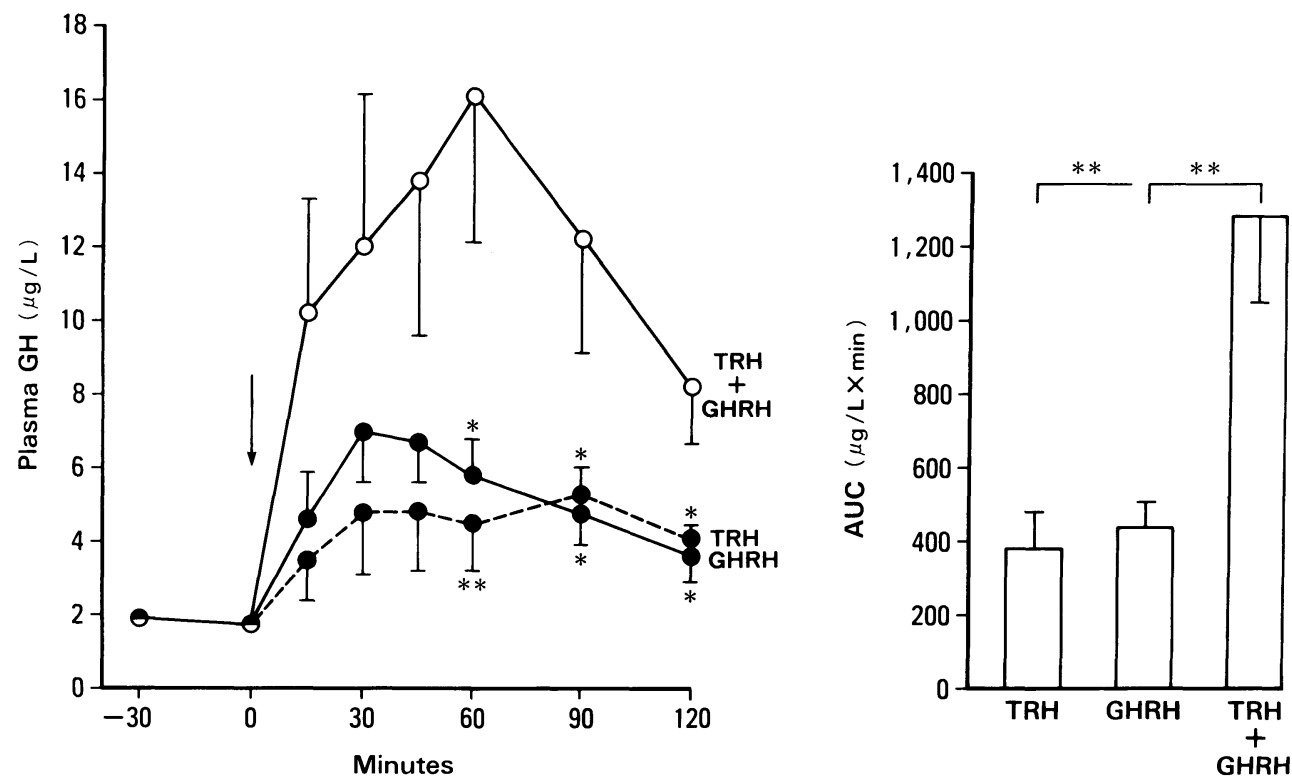

Fig. 1. Plasma GH response to TRH or GHRH individually and in combination in 7 patients with primary hypothyroidism. The AUC (area under the curve) over the baseline was calculated by trapezoidal integration. TRH $+\mathrm{GHRH}$ vs. TRH or GHRH, ${ }^{*} P<0.05 ;{ }^{* *} P<0.01$.

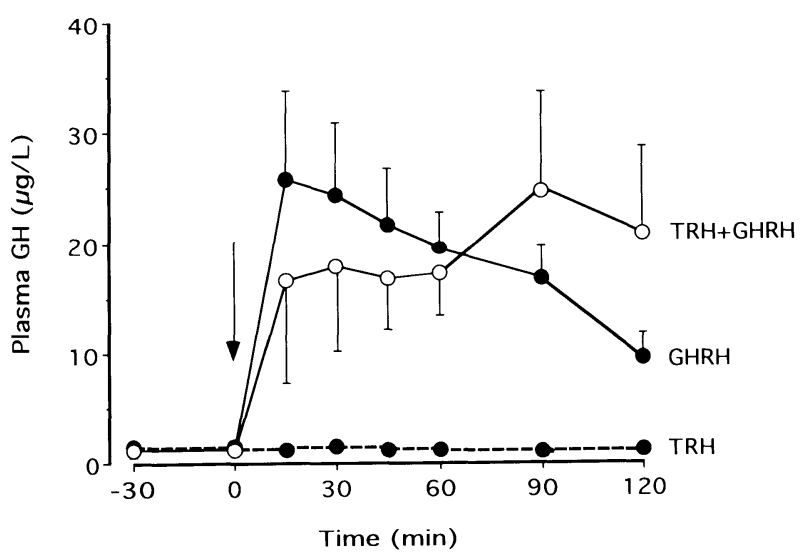

Fig. 2. Plasma GH response to TRH or GHRH individually or in combination in 8 normal subjects.

GHRH but abberant plasma GH response to TRH, and this response was enhanced by the simultaneous administration of GHRH. However, normal subjects showed neither any GH response to TRH nor any enhanced response to the combined administration of TRH and GHRH.

It is well known that thyroid hormone stimulates the synthesis and secretion of $\mathrm{GH}$ and also increases GH gene transcription and GH mRNA
[8]. Hypothyroidism therefore depletes pituitary $\mathrm{GH}$, inhibits $\mathrm{GH}$ secretion and causes severe growth retardation [8]. Nevertheless, patients with hypothyroidism often show abnormal GH responses to TRH as was seen in this study $[1,9,10]$.

The exact mechanism of such abberant GH responses to TRH is not clear, but it is reported that acromegalic patients, due to the ectopic GHRH secreting tumor, and who usually have pituitary hyperplasia, show a GH response to TRH, and such a responses disappears after the removal of the ectopic tumor [11, 12]. It has also been demonstrated that acromegalic patients with constitutively activated adenylate cyclase- protein kinase A system by the mutation of stimulatory GTP (Gs) binding protein show exaggerated $\mathrm{GH}$ response to exogenous TRH [13]. In addition, TRH-induced $\mathrm{GH}$ release from rat pituitary cells is enhanced by GHRH during the perifusion experiments [7]. It is also reported that plasma GH response to TRH is more prominent in hypothyroid rats than in euthyroid rats, and that GHRH release from the hypothalamus in vitro is increased in hypothyroid rats $[5,8]$. These phenomena suggest that the paradoxical GH responses to TRH are related to the exposure of pituitary spomatotrophs to GHRH.

TRH stimulates GH release from the stored pool 
mainly via the activation of the phosphatidyl inositol-Ca $\mathrm{Ca}^{++}$system $[4,5,14]$. It is therefore probable that significant amounts of $\mathrm{GH}$ are stored even in hypofunctional somatotrophs of patients with primary hypothyroidism. Relating to this, Valcavi et al. have observed that pyridostigmine (a cholinesterase inhibitor) or arginine, which stimulates GH secretion through the inhibition of hypothalamic somatostatin release, enhanced the plasma GH responses to GHRH in patients with primary hypothyroidism, and they have indicated the considerable somatotroph secretory capacity of these patients [15].

In contrast, GHRH stimulates the secretion of GH primarily from the newly synthesized pool mainly through activation of the stimulatory GTP binding (Gs) protein- adenylate cyclase system [14]. The blunted GH response to GHRH seen in hypothyroid patients might be closely related to disorders of hormone synthesis [8, 16, 17].

Taken together, it is conceivable that the enhanced GH responses to the simultaneous administration of TRH and GHRH are induced by the stimulation of the distinct intracellular transduction pathways. There may be no interaction between the pathways since the GH response to the combined administration was additive, but not synergistic.
In normal subjects, when GHRH was administered together with TRH, the plasma GH response was somewhat suppressed for $60 \mathrm{~min}$ and enhanced thereafter. Although the exact reason is not clear, it is possible that TRH exerts some inhibitory effects on GHRH-induced GH release, as $\mathrm{GH}$ responses to secretagogues were suppressed by TRH infusion [18, 19], and caused postinhibitory $\mathrm{GH}$ increases.

Further studies are required to determine, 1) if normal somatotrophs possess TRH receptors in a masked state, and 2) if such receptors are unmasked in the several pathologic states.

In conclusion, abnormal GH response to TRH seen in patients with primary hypothyroidism appears to act by means of a mechanism distinct from GHRH.

\section{Acknowledgement}

We are grateful to Dr. Gregory T. Brophy for his careful review of our manuscript. We thank Miss Kumi Kikuchi and Rie Aizawa for their secretarial assistance.

This work was supported in part by a grant from the Intractable Disease Division, Public Health Bureau, Ministry of Health and Welfare, Japan.

\section{References}

1. Müller EE, Nistico G (1989) Thyrotropin-releasing hormone. In: Brain Messengers and The Pituitary. Academic Press, San Diego, pp 322-335.

2. Maeda K, Kato Y, Yamaguchi N, Chihara K, Ohgo S, Iwasaki Y, Yoshimoto Y, Moridera K, Kuromaru S, Imura H (1976) Growth hormone release following thyrotropin-releasing hormone injection into patients with anorexia nervosa. Acta Endocrinol (Copenh) 81: 1-8.

3. Brazeau P, Ling N, Esch F, Bohlen P, Mougin G, Guillemin R (1982) Somatocrinin (growth hormone releasing factor) in vitro activity; $\mathrm{Ca}^{2+}$ involvement, cAMP mediated action and additivity of effect with $\mathrm{PGE}_{2}$. Biochem Biophys Res Commun 109: 588-594.

4. Rebecchi MJ, Kolesnick RN, Gershengorn MC (1983) TRH stimulates rapid loss of phosphatidylinositol and its conversion to 1,2-diacyl-glycerol and phophatidic acid in rat mammotropic pituitary cells. J Biol Chem 258: 227-234.

5. Szabo M (1986) TRH and GRF stimulate release of growth hormone through different mechanisms. Am J Physiol 250: E512-517.

6. Utsumi A, Hanew K, Sugawara A, Simizu Y, Murakami O, Yoshinaga K (1991) Plasma GH responses to combined administrations of hypothalamic hormones in patients with acromegaly. 73rd Annual Meeting of The Amer Endocrine Soc Abst. \# 206.

7. Borges JLC, Uskavitch DR, Kaiser DL, Cronin MJ, Evans WS, Thorner MO (1983) Human pancreatic growth hormone releasing factor-40 (hpGRF-40) allows stimulation of GH release by TRH. Endocrinology 113: 1519-1521.

8. Miki N, Ono M, Hizuka N, Aoki T, Demura H (1992) Thyroid hormone modulation of the hypothalamic growth hormone $(\mathrm{GH})$-releasing factor-pituitary $\mathrm{GH}$ axis in the rat. J Clin Invest 90: 113-120.

9. Collu R, Leboeuf G, Letarte J, Ducharme J-R (1977) Increase in plasma growth hormone levels following thyrotropin-releasing hormone injection in 
children with primary hypothyroidism. J Clin Endocrinol Metab 44: 743-747.

10. Faggiano M, Criscuolo T, Graziani M, Iorio S, Pisano G, Sinisi AA, Bellastella A (1985) Persistent TRHinduced grow th hormone release after short-term L-thyroxine replacement therapy in primary congenital hypothyroidism. Clin Endocrinol (Oxf) 23: 61-66.

11. Thorner MO, Perryman RL, Cronin ML, Rogol AD, Draznin M, Johanson A, Vale W, Horvath E, Kovacs K (1982) Somatotroph hyperplasia: successful treatment of acromegaly by removal of a pancreatic islet tumor secreting a growth hormone-releasing factor. J Clin Invest 70: 965-977.

12. Frohman LA, Thominet J, Szabo M, Berelowitz M (1984) Growth hormone hypersecretion, acromegaly, and extrapituitary tumors: Ectopic production of growth hormone releasing factor. In: Camanni F, Müller EE (eds) Pituitary Hyperfunction. Raven Press, New York, pp 343-353.

13. Spada A, Arosio M, Bochicchio D, Bazzoni N, Valler L, Bassetti M, Faglia G (1990) Clinical, biochemical, and morphological correlates in patients bearing growth hormone-secreting pituitary tumors with or without constitutively active adenylate cyclase. J Clin Endocrinol Metab 71: 1421-1426.

14. Stachura ME, Tyler JM, Farmer PK (1985) Human pancreatic growth hormone-releasing factor-44 dif- ferently stimulates release of stored and newly synthesized rat growth hormone in vitro. Endocrinology 116: 698-706.

15. Valcavi R, Valente F, Dieguez C, Zini M, Procopio M, Portioli I, Ghigo E (1993) Evidence against depletion of the growth hormone (GH)-releasable pool in human primary hypothyroidism: studies with GH-releasing hormone, pyridostigmine, and arginine. J Clin Endocrinol Metab 77: 616-620.

16. Martial JA, Baxter JD, Goodman HM, Seeburg PH (1977) Regulation of growth hormone messenger RNA by thyroid and glucocorticoid hormones. Proc Natl Acad Sci USA 74: 1816-1820.

17. Katakami H, Downs TR, Frohman LA (1986) Decreased hypothalamic growth hormone-releasing hormone content and pituitary responsiveness in hypothyroidism. J Clin Invest 77: 1704-1711.

18. Maeda K, Kato Y, Chihara K, Ohgo S, Iwasaki Y, Imura H (1975) Suppression by thyrotropin-releasing hormone (TRH) of human growth hormone release induced by L-dopa. J Clin Endocrinol Metab 41: 408-411.

19. Maeda K, Kato Y, Chihara K, Ohgo S, Iwasaki Y, Abe H, Imura H (1976) Suppression by thyrotropin-releasing hormone (TRH) of growth hormone release induced by arginine and insulin-induced hypoglycemia in man. J Clin Endocrinol Metab 43: 453-456. 